\title{
QUANTITATIVE RELATIONS OF ACOUSTIC INERTIAL CAVITATION WITH SONOPORATION AND CELL VIABILITY
}

\author{
Chun-Yen Lai, ${ }^{*}$ Chia-Hsuan Wu, ${ }^{\dagger}$ Chia-Chun Chen, ${ }^{\dagger}$ and PaI-Chi Li* \\ *Department of Electrical Engineering, National Taiwan University, Taipei, Taiwan; and Department of Chemistry, \\ National Taiwan Normal University, Taipei, Taiwan
}

(Received 6 December 2005; revised 12 June 2006; in final form 22 June 2006)

\begin{abstract}
Ultrasound-induced acoustic cavitation assists gene delivery, possibly by increasing the permeability of the cell membranes. How the cavitation dose is related to the sonoporation rate and the cell viability is still unknown and so this in vitro study quantitatively investigated the effects of cavitation induced by 1-MHz pulsed ultrasound waves and the contrast agent Levovist ${ }^{\circledR}$ (containing microbubbles when reconstituted by adding saline and shaken) on the delivery of short DNA-FITC molecules into HeLa cells. The concentrations of cells and DNA-FITC were $2 \times 10^{5}$ cells $/ \mathrm{mL}$ and $40 \mu \mathrm{g} / \mathrm{mL}$, respectively. The cavitation was quantified as the inertial cavitation dose (ICD), corresponding to the spectral broadband signal enhancement during microbubble destruction. The relations of ICD with sonoporation and cell viability were examined for various acoustic pressures $(0.48-1.32 \mathrm{MPa})$, Levovist ${ }^{\circledR}$ concentrations $\left(1.12 \times 10^{5}-1.12 \times 10^{7}\right.$ bubbles $\left./ \mathrm{mL}\right)$ and pulse durations (1-10 cycles). The linear regressions of the sonoporation rate versus ICD and the cell viability versus ICD were $y=28.67 x+10.71\left(R^{2}=0.95\right)$ and $z=-62.83 x+91.18\left(R^{2}=0.84\right)$, respectively, where $x$ is ICD, $y$ is the sonoporation rate and $z$ is the cell viability. These results show that the sonoporation rate and the cell viability are highly correlated with the ICD, indicating that sonoporation results may be potentially predicted using ICD. (E-mail: paichi@cc.ee.ntu.edu.tw) (C) 2006 World Federation for Ultrasound in Medicine \& Biology.
\end{abstract}

Key Words: Ultrasound, Cavitation, Levovist ${ }^{\circledR}$, Sonoporation, Inertial cavitation dose, HeLa.

\section{INTRODUCTION}

Gene therapy is a promising therapeutic technique whose purpose is to deliver to target cells a foreign therapeutic gene or drug that instigates a procedure to repair defective genes or to compensate for deficient functioning. Gene delivery is a key to gene therapy, and the delivery systems are divided into virus- and nonvirus-mediated systems (Nishikawa and Huang 2001; Robbins and Ghivizzani 1998; Schatzlein 2001). Viruses are good vectors for delivering specific genes to hosts and they have reached clinical trials for some diseases (Edelstein et al. 2004; Herman et al. 1999; Kerr 2003; Rainov 2000; Sterman et al. 1998). However, virus-mediated systems exhibit disadvantages (e.g., mutagenesis, activation of immune responses, cytotoxicity and limited DNA capacity) that are not exhibited by nonvirus-mediated gene delivery systems such as electroporation, microinjection, gene gun, liposome fusion and calcium phosphate pre-

Address correspondence to: Pai-Chi Li, Department of Electrical Engineering, National Taiwan University, No. 1, Sec. 4, Roosevelt Road, Taipei 106, Taiwan. E-mail: paichi@cc.ee.ntu.edu.tw cipitation. However, nonviral methods exhibit a lower delivery efficiency and fewer applications.

Ultrasound has been applied to gene delivery in recent years and has the advantages over other mechanical systems of noninvasiveness and the ability to focus at considerable depth. Ultrasound systems are suitable for both in vitro and in vivo therapies (Manome et al. 2000; Newman et al. 2001). Contrast agents encapsulating gas have been used in combination with ultrasound to improve the transfection efficiency. Koch et al. (2000) used 2-MHz pulsed Doppler ultrasound, cationic liposome/green fluorescent protein (GFP) plasmid DNA complex and the ultrasound contrast agent Levovist ${ }^{\circledR}$ to enhance the transfection rate to $5.5 \%$ in J3T dog brain tumor cells and showed a cell viability of $39.3 \%$. Miller et al. (2003) applied low-power diagnostic ultrasound and the contrast agent Optison ${ }^{\circledR}$ to epidermoid cells and achieved a $3.7 \%$ GFP transfection rate and a cell viability of $71.4 \%$. Greenleaf et al. (1998) applied 1-MHz continuous-wave ultrasound and the contrast agent Albunex ${ }^{\circledR}$ to human chondrocytes and achieved a 50\% GFP transfection rate. Chen et al. (2004) used the contrast agent 
Definity ${ }^{\circledR}$ to enhance the gene delivery rate in HeLa cells and achieved transfection rates up to $26 \%$. In the above research works, a flow cytometer was used to count the percentage of cells with fluorescence, and the percentage of transfected cells was determined by counting 10000 viable cells (i.e., dead cells and fragments were excluded).

Cavitation is the process of microbubble formation, resonance and destruction and microbubble-based ultrasound contrast agents act as nuclei for the induction of cavitation. Cavitation may occur when microbubbles are exposed to a time-varying acoustic field of sufficient intensity and the destruction energy can be beneficial in nonthermal treatments (Kondo and Kano 1987; Miller et al. 2000, 2002; Miller and Song 2002). An in vitro study showed that, in inertial cavitation, the violent expansion, contraction and collapse of gas bubbles was related to hemolysis (Chen et al. 2003) and that the dose of inertial cavitation can be evaluated by measuring the power emitted during the cavitation process. Quantification methods for acoustic cavitation have been investigated by many researchers (e.g., Chen et al. 2003; Cramer and Lauterborn 1982; Everbach et al. 1997; Lauterborn and Cramer 1981). One method is to calculate the spectral broadband signal enhancement during microbubble destruction, since spectral spikes may appear at up to 30 to $40 \mathrm{MHz}$ when microbubbles are destroyed (Kruse et al. 2003).

Ultrasonic cavitation is thought to assist the delivery of molecules into a cell by transiently increasing the membrane permeability (also known as sonoporation: Bao et al. 1997; Kim et al. 1996; Tata et al. 1997; Unger et al. 2002; Van Wamel et al. 2003; Wyber et al. 1997). Nevertheless, how the cavitation dose is related to the sonoporation rate and the cell viability is still unknown. Therefore, the hypothesis of this paper is as follows. Delivery of genetic material into HeLa cells can be mediated by ultrasound-induced inertial cavitation, and the quantitative relations between inertial cavitation and both the delivery and the viability can be established.

First, an experimental set-up was developed to quantify the cavitation effects as functions of the ultrasonic parameters of acoustic pressure, microbubble concentration and pulse duration, using gas-encapsulated microbubbles $\left(\right.$ Levovist $\left.^{\circledR}\right)$. Human cervical cancer cells

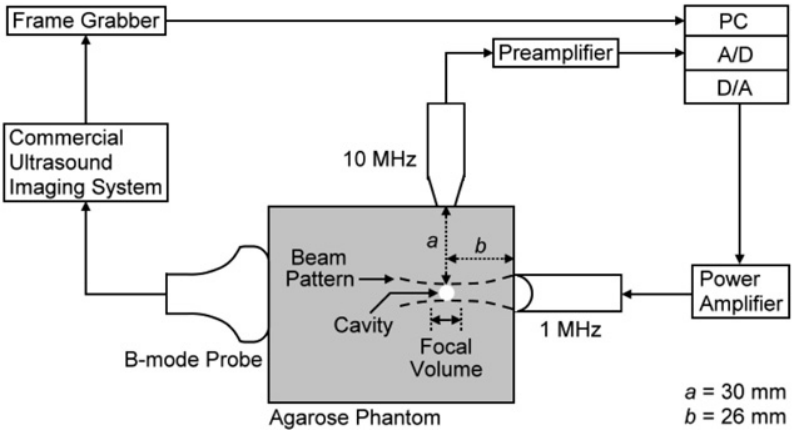

Fig. 1. Set-up of cavitation experiments.

(HeLa) and short DNA-FITC molecules were then used in the cavitation-assisted sonoporation experiments using the same ultrasonic parameters as in the cavitation experiments. The quantitative results of cavitation, sonoporation and cell viability were then used to determine how the inertial cavitation dose (ICD) was related to the sonoporation rate and the cell viability.

\section{MATERIALS AND METHODS}

\section{Cavitation experiments}

The microbubble-based contrast agent Levovist ${ }^{\circledR}$ (Schering, Berlin, Germany) was used. The size distribution and statistics of Levovist ${ }^{\circledR}$ microbubbles were measured by a particle counter (Z2 Coulter Counter, Beckman Coulter, Fullerton, CA, USA) and the diameter of the microbubbles ranged from 1 to $3 \mu \mathrm{m}$, with a mean of $1.7 \mu \mathrm{m}$. The gas content in the Levovist ${ }^{\circledR}$ microbubbles is air. The Levovist ${ }^{\circledR}$ suspension was prepared as follows. An appropriate amount of saline was added to a vial containing Levovist ${ }^{\circledR}$ granules. The vial was then shaken vigorously for about $15 \mathrm{~s}$ by hand; after 2 min the solution was ready for use. In this study, Levovist ${ }^{\circledR}$ microbubbles were used as cavitation nuclei at concentrations from $1.12 \times 10^{5}$ to $1.12 \times 10^{7}$ bubbles $/ \mathrm{mL}$ (equals to $1-100 \mathrm{mg} / \mathrm{mL}$ solutions), as determined empirically.

The cavitation experiments were performed using the set-up shown in Fig. 1. A cylindrical cavity $5 \mathrm{~mm}$ in diameter and $2.5 \mathrm{~cm}$ deep was made in an agarose phantom ( $2 \%$ concentration) as a container for the mi-

Table 1. Parameters used in the acoustic pressure, microbubble concentration and pulse duration cavitation experiments

\begin{tabular}{lccc}
\hline \multicolumn{1}{c}{ Parameter investigated } & Acoustic pressure & Microbubble concentration & Pulse duration \\
\hline Acoustic pressure (MPa) & $0.09-1.32$ & 1.32 & 1.32 \\
Microbubble concentration (bubbles/mL) & $4.5 \times 10^{6}$ & $1.12 \times 10^{5}-1.12 \times 10^{7}$ & $5.5 \times 10^{6}$ \\
Pulse duration (cycles) & 5 & 5 & $1-10$ \\
\hline
\end{tabular}




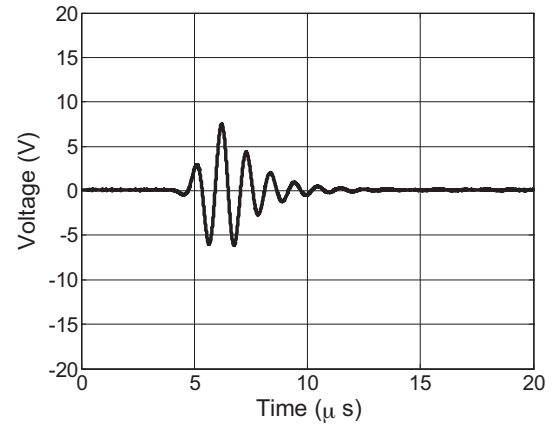

(a)

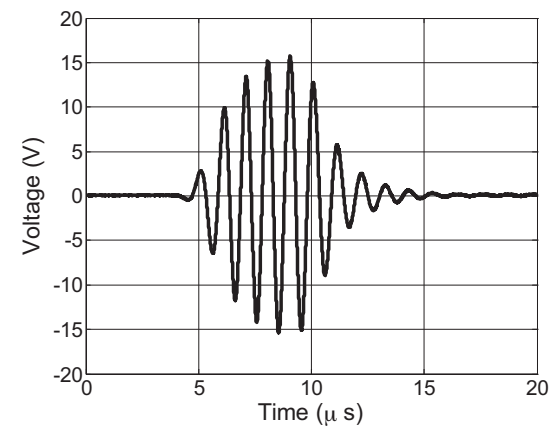

(c)

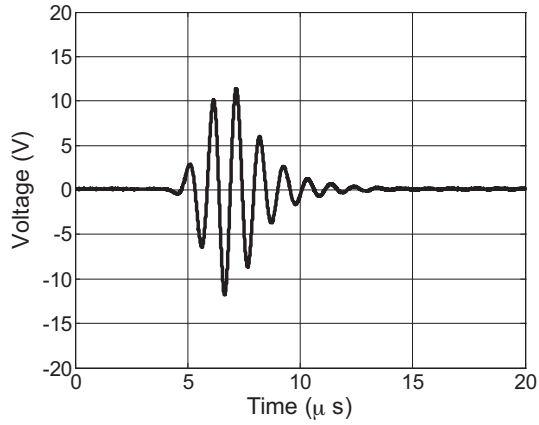

(b)

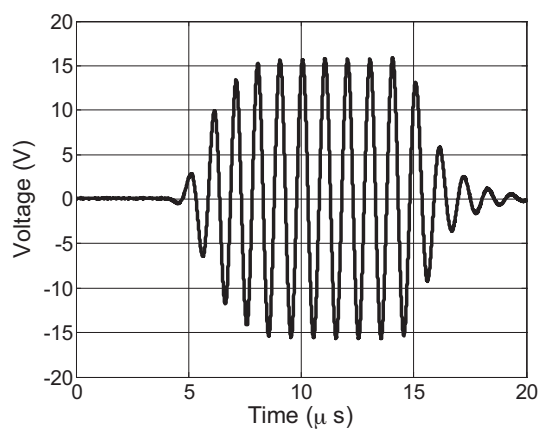

(d)

Fig. 2. The actual waveforms transmitted by the 1-MHz transducer. (a) One cycle. (b) Two cycles. (c) Five cycles. (d) 10 cycles.

crobubble solution. A 1-MHz cylindrical focused transducer (V303, Panametrics-NDT, Waltham, MA, USA) was used to induce cavitation and an unfocused $10-\mathrm{MHz}$ transducer (V312, Panametrics-NDT) was used to receive signals from the microbubbles during insonification. The two transducers were positioned perpendicular to each other and both were focused at the cavity. The distance between the cavity and the $1-\mathrm{MHz}$ transducer was $26 \mathrm{~mm}$ (equal to the focal length of the $1-\mathrm{MHz}$ transducer) and that between the cavity and the $10 \mathrm{MHz}$ transducer was $30 \mathrm{~mm}$. The $-6-\mathrm{dB}$ focal zone of the $1-\mathrm{MHz}$ transducer covered the entire cavity. The transmitted waveforms were generated by a digital-to-analog converter (CompuGen 1100, GaGe Applied Technologies, Lachine, QC, Canada) and amplified by a power amplifier (250A250A, Amplifier Research, Souderton, PA, USA). Pulsed waves were used in this study, with a pulse repetition frequency of $100 \mathrm{~Hz}$. After the microbubbles were insonified, the $10-\mathrm{MHz}$ transducer was used for detection. The received signals were sent to an ultrasonic receiver (5072PR, Panametrics-NDT) for further amplification, to match the dynamic range of the analog-to-digital converter (CompuScope 12100, GaGe Applied Technologies) used to digitize the received signals, which were analyzed using Matlab (Mathworks, Natick, MA, USA) software. A commercial ultrasound imaging system (10L probe and LOGIQ 500 system, GE Medical Systems, Milwaukee, WI, USA) was used to capture B-mode images for real-time observations of the microbubble solution.

Accurately to measure cavitation and to avoid interference, cavitation experiments and sonoporation experiments were carried out separately. The acoustic pressure of the transducer was calibrated by a radiation force balance (National Physical Laboratory, Teddington, Middlesex, UK) and a needle-type hydrophone (MHA150, FORCE Technology, Brøndby, Denmark). The maximum acoustic pressure induced by the 1-MHz transducer was $1.32 \mathrm{MPa}$. The following three ultrasonic parameters were investigated in this study: acoustic pressure, microbubble concentration and pulse duration (the parameters used are listed in Table 1).

The effects of acoustic pressure on cavitation were investigated for negative acoustic peak pressures of 0.09 , $0.25,0.48,0.79,1.09$ and $1.32 \mathrm{~Pa}$, with the microbubble concentration fixed at $4.5 \times 10^{6}$ bubbles $/ \mathrm{mL}$ and the pulse duration fixed at five cycles. The effects of microbubble concentration were also investigated using microbubble concentrations of $1.12 \times 10^{5}, 5.6 \times 10^{5}, 1.12 \times$ $10^{6}, 2.25 \times 10^{6}, 4.5 \times 10^{6}$ and $1.12 \times 10^{7}$ bubbles $/ \mathrm{mL}$, with the acoustic pressure fixed at $1.32 \mathrm{MPa}$ and the pulse duration fixed at five cycles. 

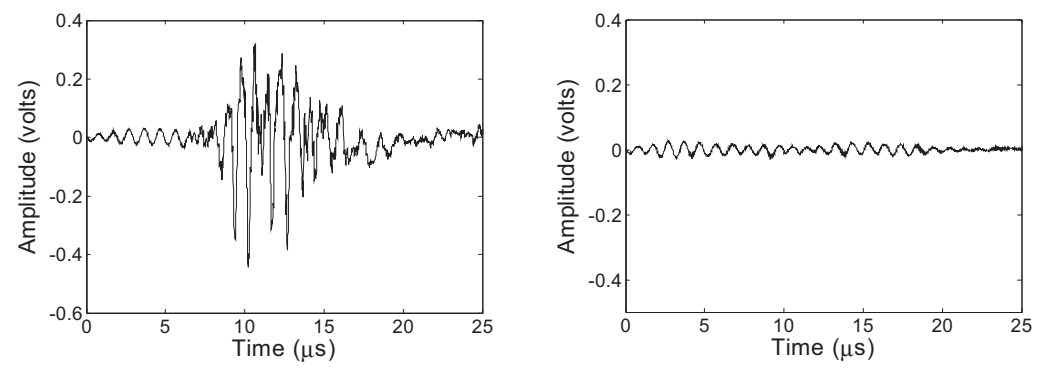

(a)

(b)
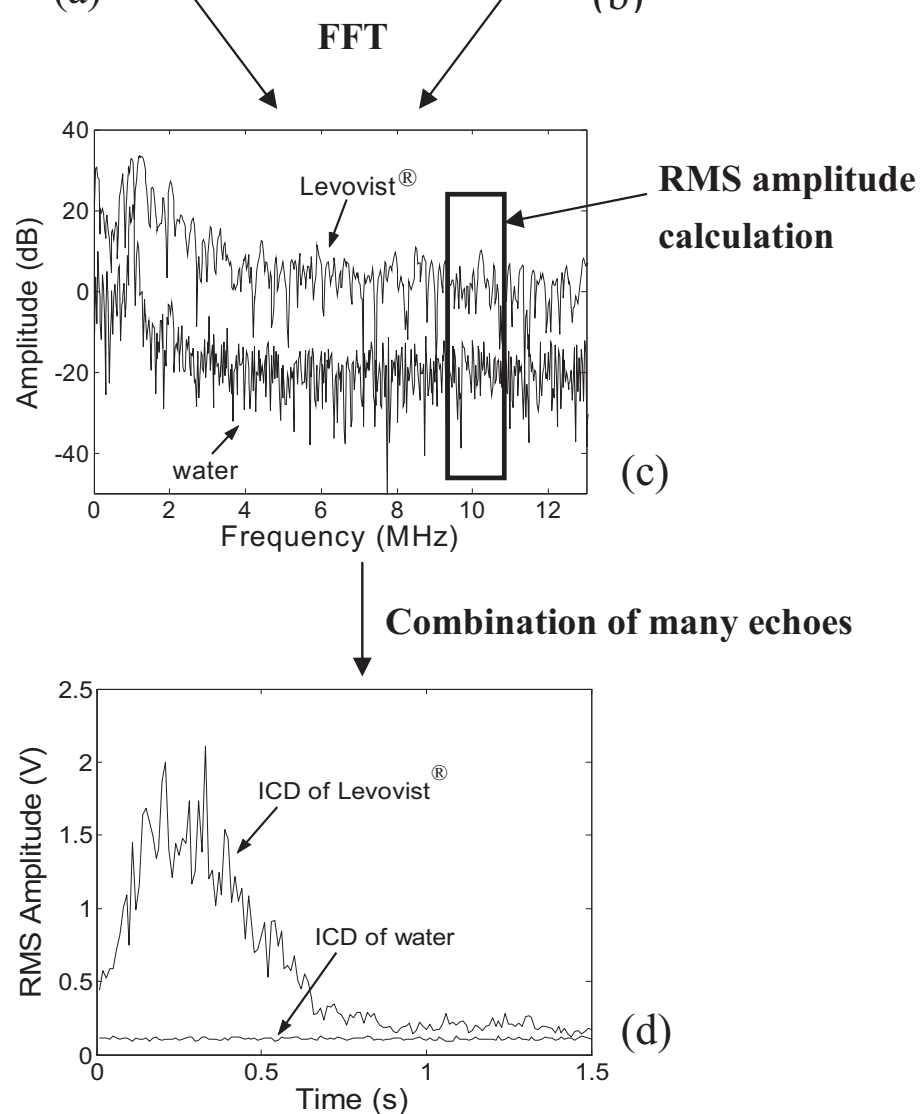

(d)

Fig. 3. The procedure for ICD calculations. (a) Signal indicating the destruction of Levovist ${ }^{\circledR}$ microbubbles. (b) Signal from water only. (c) Spectra of the signals shown in (a) and (b). (d) RMS amplitude as a function of time.

The effects of pulse durations of $1,2,5$ and 10 cycles (sine waves) on cavitation were investigated, with the acoustic pressure fixed at $1.32 \mathrm{MPa}$ and the microbubble concentration fixed at $4.5 \times 10^{6}$ bubbles $/ \mathrm{mL}$. The actual waveforms transmitted by the $1-\mathrm{MHz}$ transducer are shown in Fig. 2. Cavitation was detected by qualitative real-time image observation and quantitative signal analysis. A commercial ultrasound imaging system (LOGIQ 500/10L, GE Medical Systems) was used to acquire B-mode images. The acoustic output power was set at near $0 \%$, to avoid microbubble destruction by the imaging system. The images were captured by a frame grabber (UPG 401B, UPMOST, Taipei, Taiwan) hosted on a PC.
The inertial cavitation was quantified by measuring ICD, as shown in Fig. 3. A 10-MHz transducer was used to detect the broadband signal enhancement and to avoid harmonics of the $1-\mathrm{MHz}$ transmitted signals. Figs $3 \mathrm{a}$ and $\mathrm{b}$ show the signals captured during microbubble destruction and in the absence of microbubbles, respectively; the two corresponding spectra are shown in Fig. 3c. The ICD was quantified as the root-mean-square (RMS) value of the spectrum between 9.5 and $10.5 \mathrm{MHz}$. In this study, 150 firings with a pulse repetition frequency of $100 \mathrm{~Hz}$ were performed (i.e., the total signal capture time was $1.5 \mathrm{~s})$. A plot of the RMS amplitude as a function of time (as in Fig. 3d) represents the cavitation dose over the 1.5 -s period. Finally, the background time-amplitude 
Table 2. Parameters used in the acoustic pressure, microbubble concentration and pulse duration sonoporation experiments

\begin{tabular}{lccc}
\hline \multicolumn{1}{c}{ Parameter investigated } & Acoustic pressure & Microbubble concentration & Pulse duration \\
\hline HeLa cells $($ per $0.5 \mathrm{~mL})$ & $1 \times 10^{5}$ & $1 \times 10^{5}$ & $1 \times 10^{5}$ \\
DNA-FITC $(\mu \mathrm{g} / 0.5 \mathrm{~mL})$ & 20 & 20 & 20 \\
$\mathrm{Ca}^{2+}(\mu \mathrm{L} / 0.5 \mathrm{~mL})^{*}$ & 5 & 5 & 5 \\
Acoustic pressure $(\mathrm{MPa})_{\text {Microbubble concentration (bubbles } / \mathrm{mL})}$ & $0.48-1.32$ & 1.32 & 1.32 \\
Pulse duration $($ cycles) & $4.5 \times 10^{6}$ & $5.12 \times 10^{6}-1.12 \times 10^{7}$ & $5.5 \times 10^{6}$ \\
Exposure time $(\mathrm{s})$ & 60 & 60 & $1-10$ \\
\hline
\end{tabular}

* The concentration of the $\mathrm{Ca}^{2+}$ solution was $2.5 \mathrm{~mol} / \mathrm{L}$.

curve (the measured RMS amplitudes from water only) was subtracted and the resulting amplitude is referred to as the differential ICD that was used for subsequent signal analysis. The parameters are derived from the following equations:

$$
\mathrm{ICD}=\int_{0 s}^{1.5 s}(\text { time-amplitude curve }) d t
$$

\section{Differential ICD}

$$
\begin{aligned}
= & \left.\int_{0 s}^{1.5 s} \text { (time-amplitude curve of Levovist }\right) d t \\
& \left.-\int_{0 s}^{1.5 s} \text { (time-amplitude curve of water }\right) d t .
\end{aligned}
$$

\section{Sonoporation experiments}

Short DNA-FITC molecules were used in the sonoporation experiments. The DNA was a random assembly sequence of $5^{\prime}$-TACATCATGG-3' and FITC dye was labeled on the $5^{\prime}$ end of the DNA (MDBio, Taipei, Taiwan). Because DNA is negatively charged and the FITC dye emits green fluorescence during stimulation by light at 450 to $490 \mathrm{~nm}$, the DNA-FITC molecules in this study not only had the required DNA characteristics but could also be visualized. Before being adding to the cell suspension, the DNA-FITC molecules were mixed with

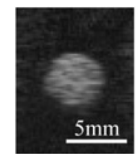

(a)

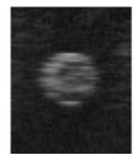

(b)

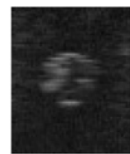

(c)

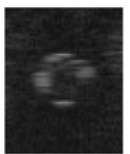

(d)

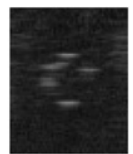

(e)

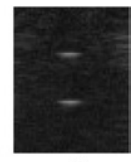

(f)
Fig. 4. B-mode images before and during ultrasound exposure at (a) $0 \mathrm{~s}$ (before ultrasound exposure) and at (b) 0.5, (c) 0.75, (d) 1, (e) 2 and (f) $3 \mathrm{~s}$. calcium ions (at a concentration of $2.5 \mathrm{~mol} / \mathrm{L}$ ) to enhance the attraction between DNA-FITC molecules and the cell membrane (Graham et al. 1973). In this study, the concentration of DNA-FITC molecules was fixed at $40 \mu \mathrm{g} /$ $\mathrm{mL}$.

Cervical cancer cells (HeLa) were cultured on culture plates as a monolayer in Dulbecco's modified Eagle's medium (DMEM, GIBCO, Grand Island, NY, USA) with $10 \%$ fetal bovine serum (GIBCO) and $1 \%$ penicillin (GIBCO) in a $37^{\circ} \mathrm{C}$ humidified incubator $(5 \%$ $\mathrm{CO}_{2}$ ). Before sonoporation experiments, cells were trypsinized and quantified using a hematocytometer, and then divided into $0.5-\mathrm{mL}$ aliquots in each Eppendorf tube, which contained DMEM, serum and $10^{5}$ suspended cells. After cell preparation, the mixture of DNA-FITC molecules and calcium ions was added to the cell suspension. Microbubbles were added to this solution, which was then exposed to ultrasound. At the same time, they were sham-exposed to ultrasound for comparisons with the experimental sets.

The set-up for sonoporation experiments was the same as that in cavitation experiments, except for the inclusion of the $10-\mathrm{MHz}$ transducer and the use of a commercial ultrasound imaging system. Before ultra-

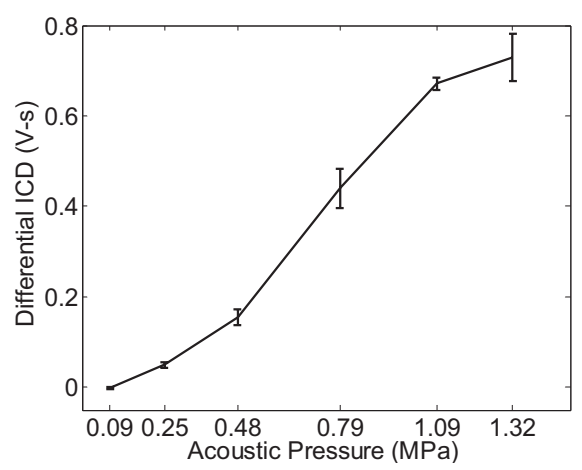

Fig. 5. Differential ICD as a function of acoustic pressure (microbubble concentration: $4.5 \times 10^{6}$ bubbles $/ \mathrm{mL}$, pulse duration: five cycles). Each point represents the mean and standard deviation for four independent trials $(n=4)$. 


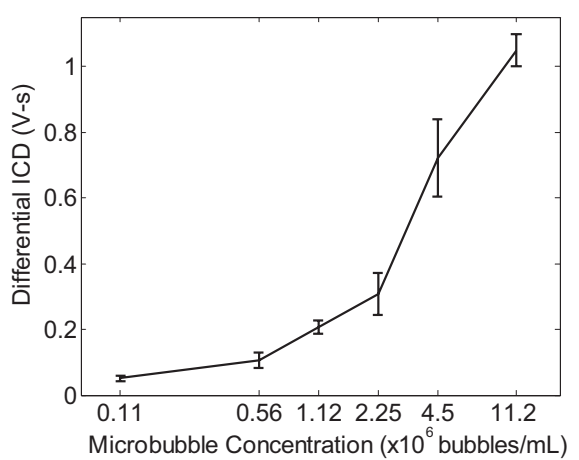

Fig. 6. Differential ICD as a function of microbubble concentration, with a logarithmic concentration axis (acoustic pressure: $1.32 \mathrm{MPa}$; pulse duration: five cycles). Each point represents the mean and standard deviation for four independent trials $(n=4)$.

sound exposure, Levovist ${ }^{\circledR}$ microbubbles were added to the Eppendorf tube containing the mixture of cells, DNA-FITC molecules and calcium ions. The tube was then vigorously shaken for $15 \mathrm{~s}$ and left to stand for 2 min to allow microbubbles to form, after which the mixed solution was injected into the cavity inside the phantom for exposure to ultrasound. The parameters in the sonoporation experiments were as follows: acoustic pressures of $0.48,0.79,1.09$ and $1.32 \mathrm{MPa}$; microbubble concentrations of $1.12 \times 10^{6}, 2.25 \times 10^{6}, 4.5 \times 10^{6}$, and $1.12 \times 10^{7}$ bubbles $/ \mathrm{mL}$; and pulse durations of $1,2,5$ and 10 cycles. The ultrasound exposure time was $60 \mathrm{~s}$ (this time duration was chosen to follow the previous transfection studies but, nonetheless, the microbubbles were destroyed in the first few seconds), after which the mixed solution was removed from the cavity and cultured on a culture plate for $24 \mathrm{~h}$. At the $24 \mathrm{th} \mathrm{h}$, the nonadherent cells (mostly dead cells), fragments of cells, microbubble shells and DNA-FITC molecules that had not been taken up were washed out with $1 \times$ phosphatebuffered saline solution and then replaced with new DMEM medium. After an additional $24 \mathrm{~h}$ (i.e., at the 48th $\mathrm{h}$ ), the DMEM was washed out and replaced by $1 \times$ phosphate-buffered saline again and the cells were observed. The parameters used in the sonoporation experiments are listed in Table 2 and, for each experimental regimen, there were three independent trials.

The sonoporation rate was determined under $200 \times$ fluorescence microscopy (TCS SP2, Leica Camera, Solms, Germany). Green fluorescence was present when the DNA-FITC molecules were taken up by the cells and, hence, the sonoporation rate was estimated by calculating the proportion of cells that exhibited green fluorescence in five regions-of-interest on the culture plate (top, bottom, left, right and middle). The survival was assessed using a trypan blue assay: cells were immersed in trypan blue dye and dead cells appeared to be blue, due to permeation by the dye. Cell viability was also estimated by comparing the total number of living cells in the five regions of interest between samples exposed to ultrasound exposure and the control samples (i.e., those without ultrasound exposure, DNA-FITC molecules and microbubbles).

\section{RESULTS}

\section{Cavitation measurements}

Figure 4 shows B-mode images before and during ultrasound exposure. Before ultrasound exposure, the microbubbles inside the cavity of the phantom produced strong scattering signals. Turning on the $1-\mathrm{MHz}$ transducer resulted in darkening of some of the hyperecho regions, indicating the destruction of microbubbles, with the scattering signals vanishing after $3 \mathrm{~s}$ of exposure. Because the $-6-\mathrm{dB}$ focal volume of the 1-MHz transducer covered the entire cavity, it was considered that all of the microbubbles were exposed to the ultrasound irradiation.

Figure 5 shows that the differential ICD increased from 0 to 0.73 volt-second (V-s) as the acoustic pressure increased from 0.09 to $1.32 \mathrm{MPa}$; Fig. 6 shows that the differential ICD increased from 0.05 to $1.05 \mathrm{~V}$-s as the microbubble concentration increased from $1.12 \times 10^{5}$ to $1.12 \times 10^{7}$ bubbles $/ \mathrm{mL}$ and Fig. 7 shows that the differential ICD increased from 0.14 to $1.15 \mathrm{~V}$-s as the pulse duration increased from one to 10 cycles.

\section{Sonoporation experiments}

The fluorescence that occurs when DNA-FITC molecules enter a cell can be observed under a fluorescence microscope. A confocal microscope (TCS SP2, Leica Camera) was used to visualize the DNA-FITC molecules to determine whether they were inside cells and the slices captured by the confocal microscope showed that the

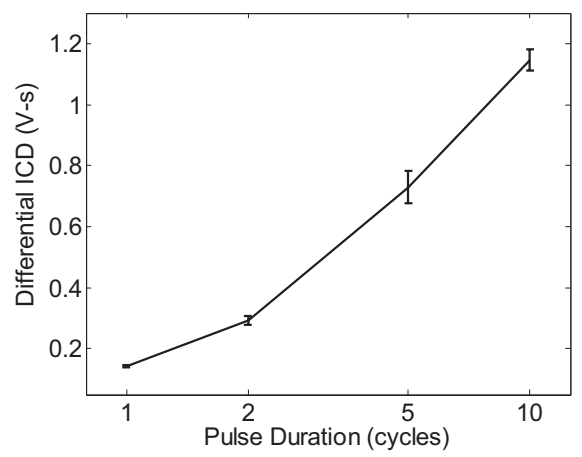

Fig. 7. Differential ICD as a function of pulse duration, with a logarithmic pulse duration axis (acoustic pressure: $1.32 \mathrm{MPa}$; microbubble concentration: $4.5 \times 10^{6}$ bubbles $/ \mathrm{mL}$ ). Each point represents the mean and standard deviation for four independent trials $(n=4)$. 


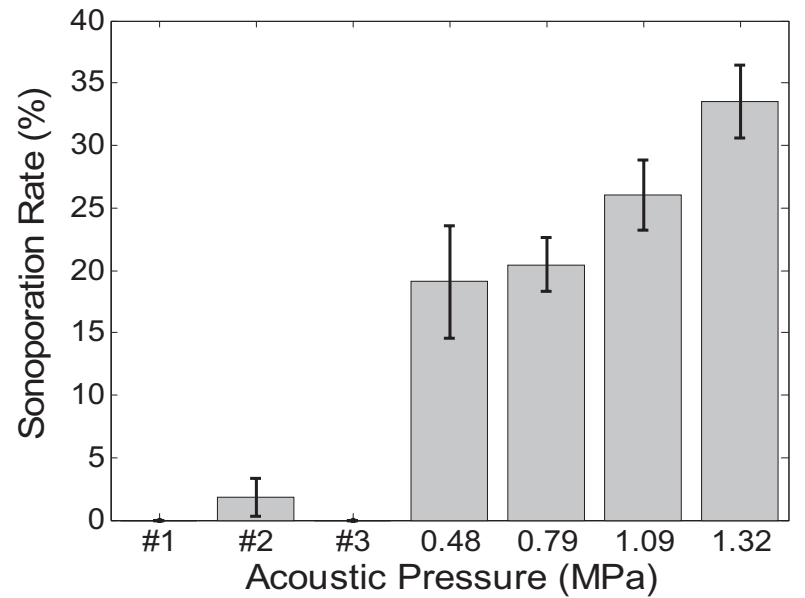

(a)

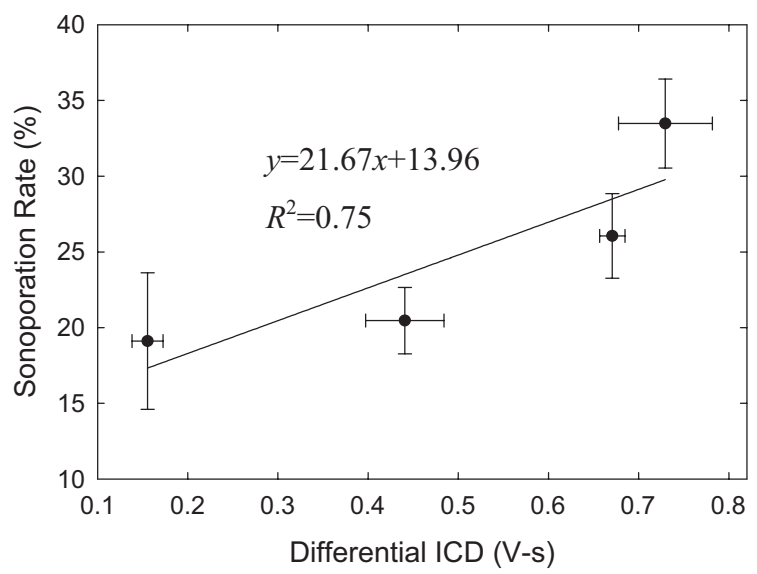

(c)

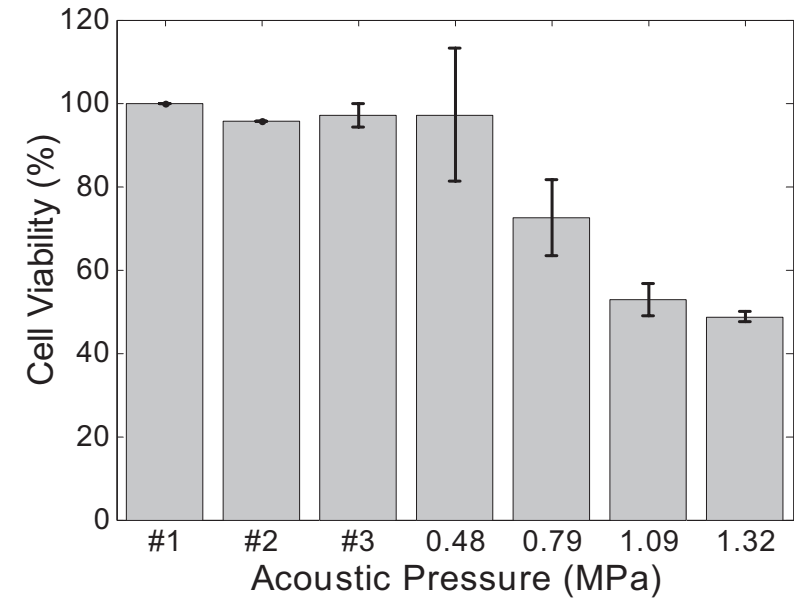

(b)

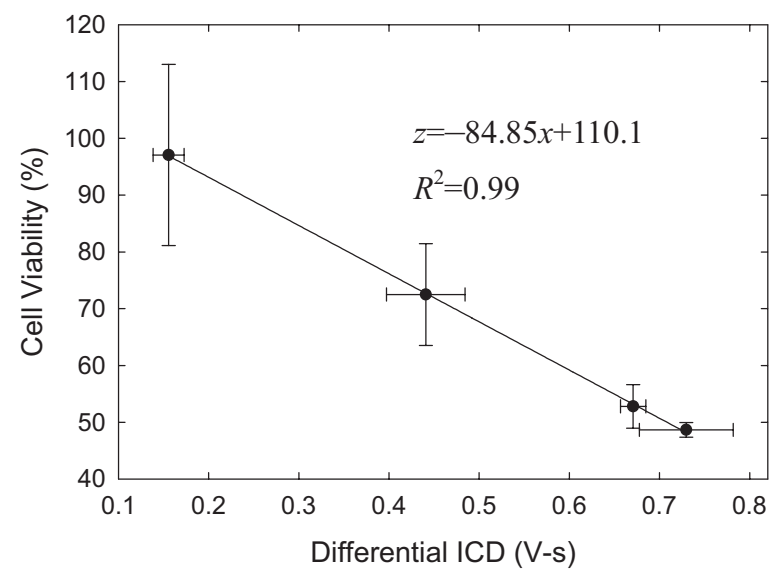

(d)

Fig. 8. (a) and (b) Sonoporation results as a function of acoustic pressure. No. 1 to no. 3 denote control sets: no. 1 only had cells; no. 2 had cells, DNA-FITC and calcium ions; and no. 3 was the same as no. 2 with the addition of ultrasound exposure. (c) and (d) Sonoporation results as functions of differential ICD. Each point represents the mean and standard deviation for three independent trials $(n=3)$.

DNA-FITC molecules were indeed absorbed to the HeLa cells, instead of being adsorbed to the outside cell membranes.

In the sonoporation experiments, three control (sham) sets were performed for comparisons with the experimental sets. The first set only included HeLa cells, which was the baseline for cell viability calculations. The second set contained HeLa cells, FITC-DNA molecules and calcium ions, but did not contain Levovist ${ }^{\circledR}$ microbubbles and was not exposed to ultrasound. This set showed the background sonoporation rate (spontaneous molecules uptake by HeLa cells). The third set was the same as the second set with the addition of ultrasound exposure. This set examined the sonoporation rate under the condition of ultrasound exposure but without cavitation. The sonoporation rate and cell viability were mea- sured using eqn 3 and eqn 4 and, during the calculation, the slides were scored blindly:

Sonoporation rate

$$
\begin{array}{r}
=\frac{\text { The number of cells with fluorescence }}{\text { The number of viable cells (after } 48 \mathrm{hr})} \\
\times 100 \%
\end{array}
$$

Cell viability

$$
\begin{array}{r}
=\frac{\text { The number of viable cells in the experimental sets }}{\text { The number of viable cells in the control sets }} \\
\times 100 \% .
\end{array}
$$

The sonoporation results are shown in Figs. 8, 9 and 10. Figures $8 \mathrm{a}$ and $\mathrm{b}$ show the sonoporation rate and the cell 


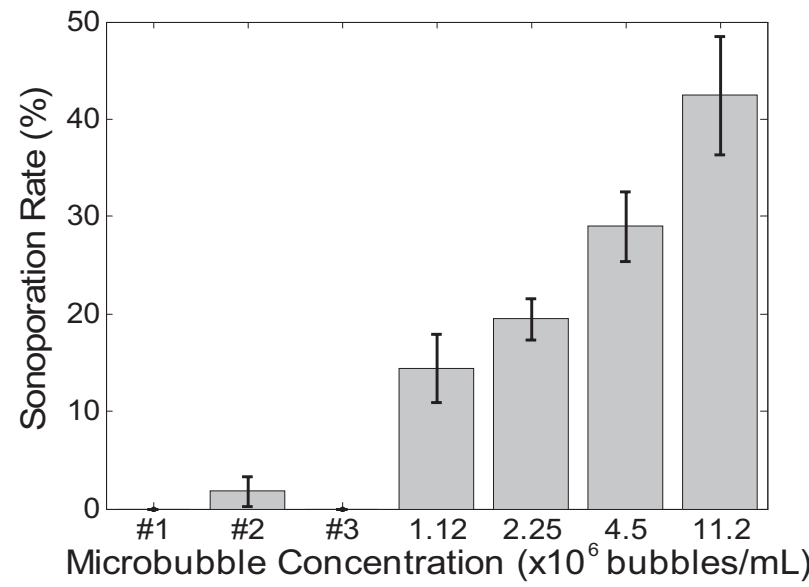

(a)

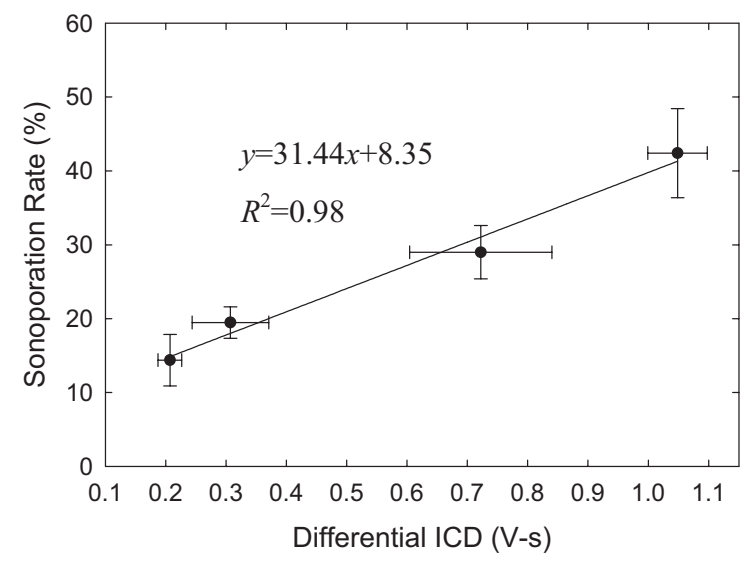

(c)

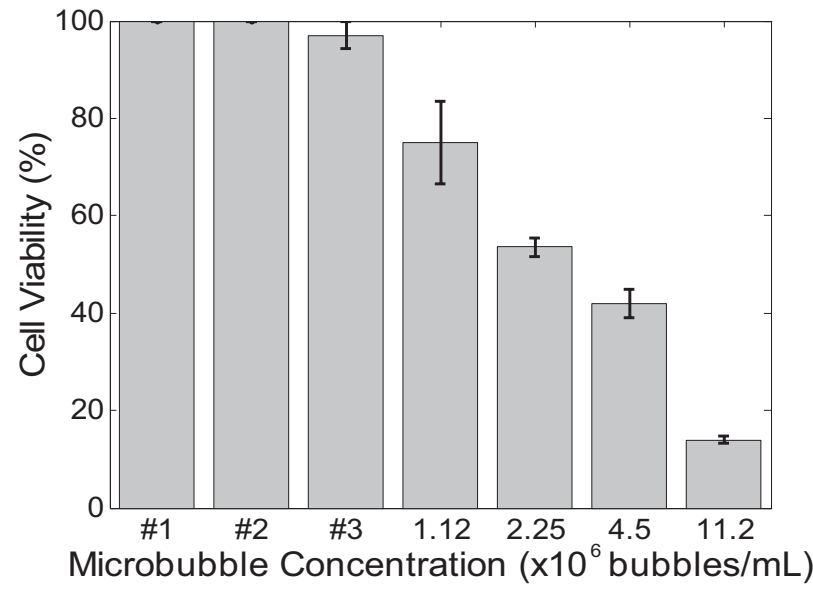

(b)

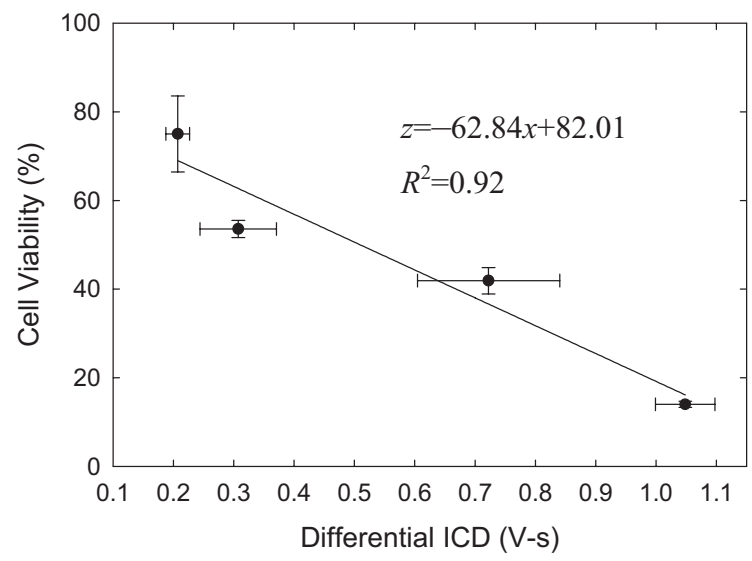

(d)

Fig. 9. (a) and (b) Sonoporation results as a function of microbubble concentration. No. 1 to no. 3 denote control sets as in Fig. 8. (c) and (d) Sonoporation results as functions of differential ICD. Each point represents the mean and standard deviation for three independent trials $(n=3)$.

viability as functions of the acoustic pressure. When acoustic pressure increased from 0.48 to $1.32 \mathrm{MPa}$, the sonoporation rate increased from $19.1 \%$ to $33.5 \%$ and the cell viability decreased from $97.1 \%$ to $48.7 \%$. Although the cavitation experiment only lasted $1.5 \mathrm{~s}$, the Levovist ${ }^{\circledR}$ microbubbles were almost destroyed in this time interval. In other words, the cavitation dose is the same as that obtained from the $60 \mathrm{~s}$ experiments. Therefore, the results of differential ICD and sonoporation can be combined. Linear regression performed on the sonoporation rate versus differential ICD and the cell viability versus differential ICD revealed correlation coefficients $\left(R^{2}\right)$ of 0.75 and 0.99 , respectively, (Fig. 8c and d). Moreover, the three control sets did not exhibit effective sonoporation (less than 3\%).

Figures $9 \mathrm{a}$ and $\mathrm{b}$ show the sonoporation rate and the cell viability as functions of the microbubble concentration. When the concentration increased from $1.12 \times 10^{6}$ to $1.12 \times 10^{7}$ bubbles $/ \mathrm{mL}$, the sonoporation rate increased from $14.4 \%$ to $42.4 \%$ and the cell viability decreased from $75.0 \%$ to $14.0 \%$. Linear regression performed on the sonoporation rate $v s$. differential ICD and the cell viability versus differential ICD revealed correlation coefficients of 0.98 and 0.92 , respectively (Fig. 9c and d). The three control sets did not exhibit effective sonoporation.

Figures 10a and $\mathrm{b}$ show the sonoporation rate and the cell viability as functions of the pulse duration. When the pulse duration increased from one to 10 cycles, the sonoporation rate increased from $16.2 \%$ to $44.7 \%$ and the cell viability decreased from $78.3 \%$ to $28.4 \%$. Linear regression performed on the sonoporation rate versus differential ICD and the cell viability versus differential ICD revealed correlation coefficients of 0.99 and 0.99 , respectively (Fig. 10c and d). The three control sets did not exhibit effective sonoporation. 


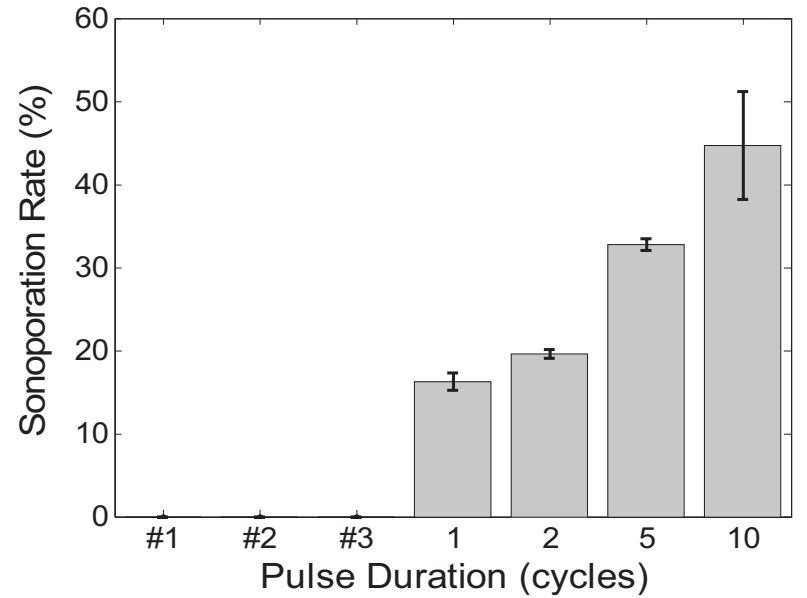

(a)

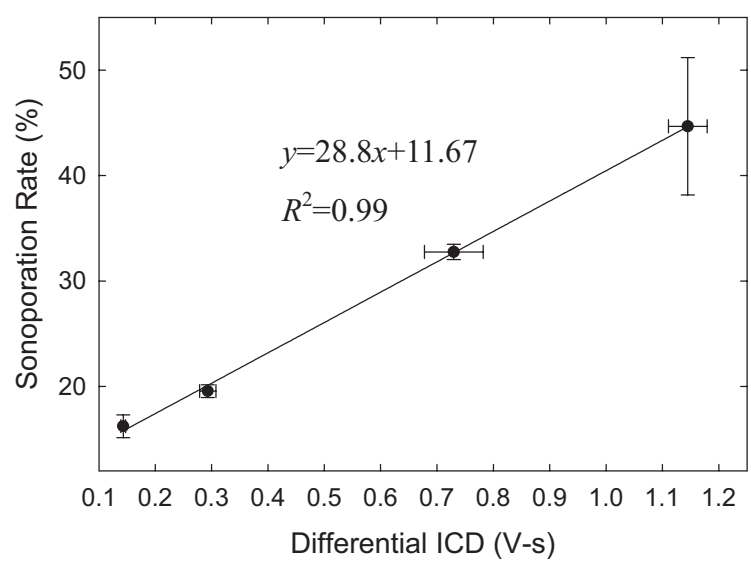

(c)

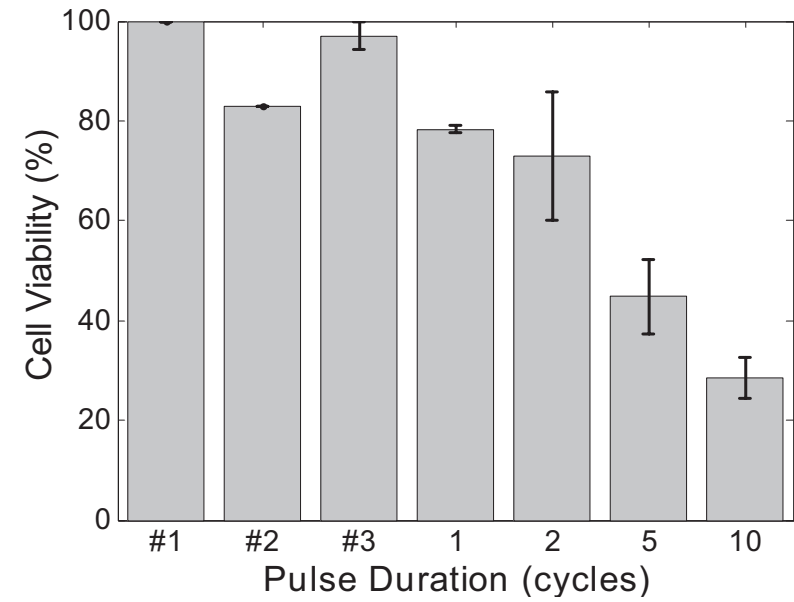

(b)

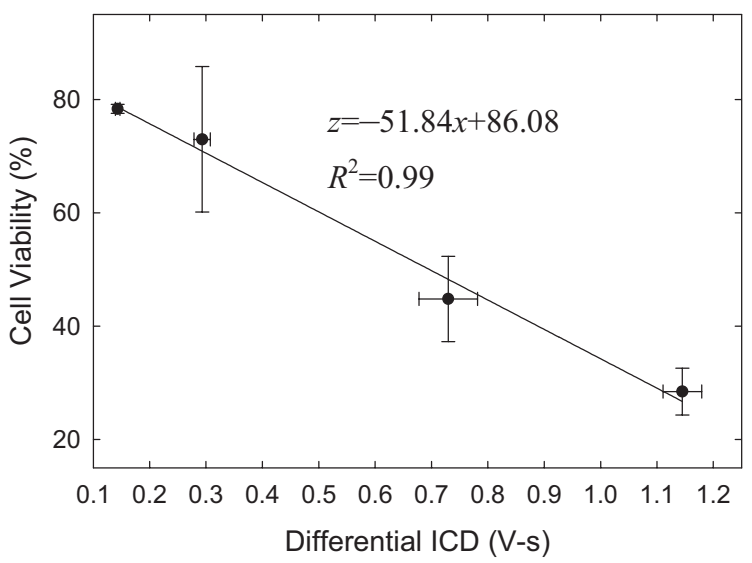

(d)

Fig. 10. (a) and (b) Sonoporation results as a function of pulse duration. No. 1 to no. 3 denote control sets as in Fig. 8. (c) and (d): Sonoporation results as functions of differential ICD. Each point represents the mean and standard deviation for three independent trials $(n=3)$.

The results in Figs. 8, 9 and 10 clearly indicate that both the sonoporation rate and the cell viability were highly correlated with the differential ICD. The second and third control sets also showed that there was very little sonoporation when ultrasound and microbubbles were not simultaneously present. Combining the results of the sonoporation rate versus differential ICD from the acoustic pressure, microbubble concentration and pulse duration measurements revealed a high correlation coefficient (Fig. $11, R^{2}=$ 0.95). Similarly, combining the results of the cell viability versus differential ICD from the three parameters also revealed a high correlation (Fig. 12, $R^{2}=$ $0.84)$. The results of Figs. 11 and 12 indicate that both the sonoporation rate and the cell viability were highly correlated with cavitation, irrespective of the source of microbubble destruction.

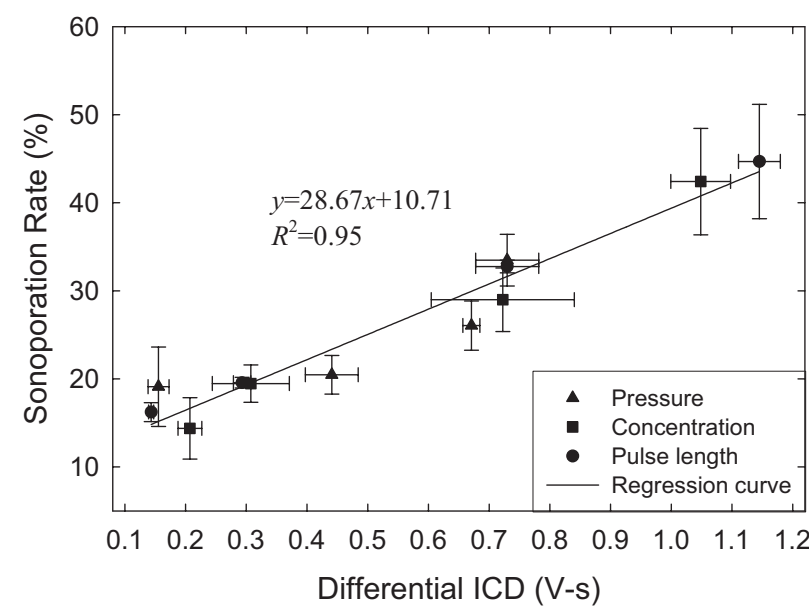

Fig. 11. Combination of all sonoporation results as a function of differential ICD. 


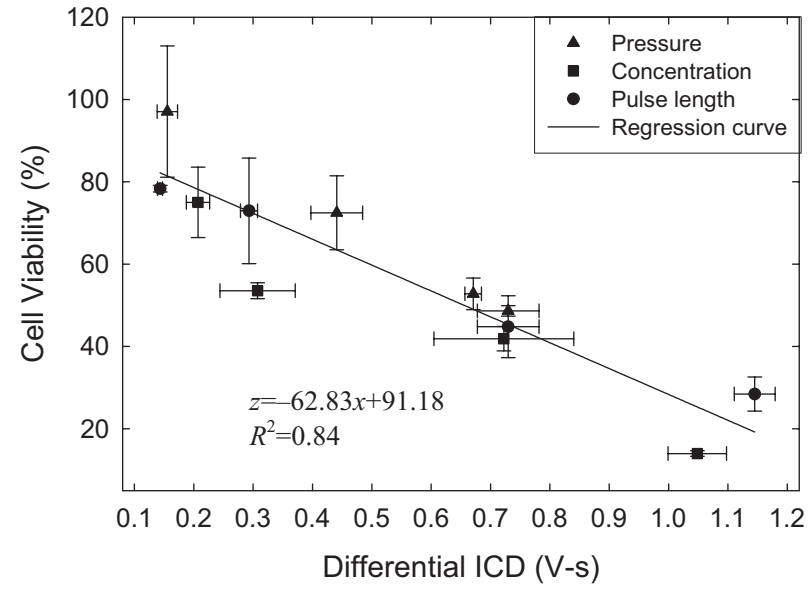

Fig. 12. Combination of all cell viability results as a function of differential ICD.

\section{DISCUSSION AND CONCLUSIONS}

The hypothesis of this paper is to examine the effects of ultrasound-induced inertial cavitation on sonoporation and the results proved that the delivery of FITCDNA molecules into HeLa cells can be mediated by IC and, the greater the IC, the greater the delivery and the less the cell viability.

In this paper, we combined gene delivery experiments and cavitation measurements to reveal that both the sonoporation rate and the cell viability are highly correlated with the differential ICD. Our experimental set-up for observing and analyzing the cavitation effects of a group of microbubbles guaranteed that a large number of microbubbles were simultaneously exposed to a time-varying acoustic field, and allowed the cavitation signals effectively to be detected and analyzed.

Some previous studies have also used Levovist ${ }^{\circledR}$ as the cavitation nuclei. For example, a 5.5\% transfection rate and a $39.3 \%$ cell viability were achieved with J3T dog brain tumor cells by Koch et al. (2000) and a 5\% transfection rate and a $60.7 \%$ cell viability were achieved with Chinese hamster ovary cells by Li et al. (2003). Different cell lines and different delivery procedures (e.g., ultrasound exposure to adherent cells or cell suspensions) may lead to different results (Oberle et al. 2004) and the sonoporation experiments in this study only examined sonoporation (i.e., uptake) of DNA-FITC molecules and not gene expression: in future work, we will use GFP plasmid for gene expression experiments. Nevertheless, the primary goal of this study was to elucidate the role of acoustic cavitation on cell membrane permeability and DNA-FITC is more appropriate for this purpose.

In some studies, the sonoporation rate was related to the duration of exposure to ultrasound (Koch et al. 2000).
The present study used an exposure time of $60 \mathrm{~s}$. Whilst the cavitation lasted for less than $1.5 \mathrm{~s}$, as shown in Fig. 3 , the subsequent ultrasound exposure may have further helped to enhance the uptake of DNA. This hypothesis will also be a subject of future work.

Acknowledgments-The authors thank M. T. Su, National Taiwan Normal University, for supporting the fluorescence microscopy and confocal microscopy. This study was financially supported by National Science Council grant NSC 94 to 2213-E-002 to 116.

\section{REFERENCES}

Bao S, Thrall BD, Miller DL. Transfection of a reporter plasmid into cultured cells by sonoporation in vitro. Ultrasound Med Biol 1997; 23:953-959.

Chen WS, Brayman AA, Matula TJ, Crum LA. Inertial cavitation dose and hemolysis produced in vitro with or without Optison ${ }^{\circledR}$. Ultrasound Med Biol 2003;29:725-737.

Chen WS, Lu X, Liu Y, Zhong P. The effect of surface agitation on ultrasound-mediated gene transfer in vitro. J Acoust Soc Am 2004, 116:2440-2450.

Cramer E, Lauterborn W. Acoustic cavitation noise spectra. Appl Sci Res 1982;38:209-214.

Edelstein ML, Abedi MR, Wixon J, Edelstein RM. Gene therapy clinical trials worldwide 1989-2004-an overview. J Gene Med 2004;6:597-602.

Everbach EC, Makin IRS, Azadniv M, Meltzer RS. Correlation of ultrasound-induced hemolysis with cavitation detector output in vitro. Ultrasound Med Biol 1997;23:619-624.

Graham FL, Van der Eb AJ. A new technique for the assay of infectivity of human adenovirus 5 DNA. Virology 1973;52:456-467.

Greenleaf WJ, Bolander ME, Sarkar G, Goldring MB, Greenleaf JF. Artificial cavitation nuclei significantly enhance acoustically induced cell transfection. Ultrasound Med Biol 1998;24:587-595.

Herman JR, Adler HL, Aguilar-Cordova E, et al. In situ gene therapy for adenocarcinoma of the prostate: A phase I clinical trial. Hum Gene Ther 1999;10:1239-1249.

Kerr D. Clinical development of gene therapy for colorectal cancer. Nat Rev Cancer 2003;3:615-622.

Kim HJ, Greenleaf JF, Kinnick RR, Bronk JT, Bolander ME. Ultrasound-mediated transfection of mammalian cells. Hum Gene Ther 1996;7:1339-1346.

Koch S, Pohl P, Cobet U, Rainov NG. Ultrasound enhancement of liposome-mediated cell transfection is caused by cavitation effects. Ultrasound Med Biol 2000;26:897-903.

Kondo T, Kano E. Enhancement of hyperthermic cell killing by nonthermal effect of ultrasound. Int J Radiat Biol Relat Stud Phys Chem Med 1987;51:157-166.

Kruse DE, Yeh CK, Ferrara KW. A new imaging strategy utilizing wideband transient response of ultrasound contrast agents. Honolulu, HI: IEEE. Ultrasonics Symposium 2003;1:424-428.

Lauterborn W, Cramer E. On the dynamics of acoustic cavitation noise spectra. Acustica 1981;49:280-287.

Li T, Tachibana K, Kuroki M, Kuroki M. Gene transfer with echoenhanced contrast agents: comparison between Albunex ${ }^{\circledR}$, Optison $^{\circledR}$ and Levovist ${ }^{\circledR}$ in mice-initial results. Radiology 2003;229: 423-428.

Manome Y, Nakamura M, Ohno T, Furuhata H. Ultrasound facilitates transduction of naked plasmid DNA into colon carcinoma cells in vitro and in vivo. Hum Gene Ther 2000;11:1521-1528.

Miller DL, Dou C, Song J. DNA transfer and cell killing in epidermoid cells by diagnostic ultrasound activation of contrast agent gas bodies in vitro. Ultrasound Med Biol 2003;29:601-607.

Miller DL, Kripfgans OD, Fowlkes JB, Carson PL. Cavitation nucleation agents for nonthermal ultrasound therapy. J Acoust Soc Am 2000; 107:3480-3486. 
Miller DL, Pislaru SV, Greenleaf JF. Sonoporation: Mechanical DNA delivery by ultrasonic cavitation. Ultrasound Med Biol 2002;27: $115-134$.

Miller DL, Song J. Lithotripter shock waves with cavitation nucleation agents produce tumor growth reduction and gene transfer in vivo. Ultrasound Med Biol 2002;28:1343-1348.

Newman CM, Lawrie A, Brisken AF, Cumberland DC. Ultrasound gene therapy: On the road from concept to reality. Echocardiography 2001;18:339-347.

Nishikawa M, Huang L. Nonviral vectors in the new millennium: Delivery barriers in gene transfer. Hum Gene Ther 2001;12:861870.

Oberle V, de Jong G, Drayer JI, Hoekstra D. Efficient transfer of chromosome-based DNA constructs into mammalian cells. Biochim Biophys Acta 2004;1676:223-230.

Rainov NG. A phase III clinical evaluation of herpes simplex virus type 1 thymidine kinase and ganciclovir gene therapy as an adjuvant to surgical resection and radiation in adults with previously untreated glioblastoma multiforme. Hum Gene Ther 2000;11:2389-2401.

Robbins PD, Ghivizzani SC. Viral vectors for gene therapy. Pharmacol Ther 1998;80:35-47.
Schatzlein AG. Non-viral vectors in cancer gene therapy: Principles and progress. Anticancer Drugs 2001;12:275-304.

Sterman DH, Treat J, Litzky LA, et al. Adenovirus-mediated herpes simplex virus thymidine kinase/ganciclovir gene therapy in patients with localized malignancy: Results of a phase I clinical trial in malignant mesothelioma. Hum Gene Ther 1998;9:10831092.

Tata DB, Dunn F, Tindall DJ. Selective clinical ultrasound signals mediate differential gene transfer and expression in two human prostate cancer cell lines: LnCap and PC-3. Biochem Biophys Res Commun 1997;234:64-67.

Unger EC, Matsunaga TO, McCreery T, Schumann P, Sweitzer R, Quigley R. Therapeutic applications of microbubbles. Eur J Radiol 2002;42:160-168.

Van Wamel A, Bouakaz A, de Jong N. Duration of ultrasound bubbles enhanced cell membrane permeability. Honolulu, HI: IEEE. Ultrasonics Symposium 2003;1:917-920.

Wyber JA, Andrews J, D'Emanuele A. The use of sonication for the efficient delivery of plasmid DNA into cells. Pharm Res 1997;14: $750-756$. 